\title{
HUBUNGAN SEKSUAL PRANIKAH PADA ANAK JALANAN DI KOTA MAKASSAR
}

\author{
Pre-Married Sexual Relationships with Street Child in Makassar City
}

\author{
Sri Kurnia Sah Puteri, Anita Kartini Herman
}

STIKES Tanawali Persada Takalar

\section{Riwayat artikel}

Diajukan: 30 Juni 2021

Diterima: 19 Agustus 2021

\section{Penulis Korespondensi: \\ - Sri Kurnia Sah Puteri \\ - $\quad$ STIKES Tanawali Persada Takalar \\ e-mail: \\ unhyendha@gmail.com}

\section{Kata Kunci:}

Hubungan

Seksual,

Pranikah, Anak Jalanan

\begin{abstract}
Abstrak
Pendahuluan : Anak jalanan merupakan sebuah realitas yang amat jelas dan dekat dengan kehidupan kita sehari-hari. Dewasa ini, pertumbuhan anak jalanan di Indonesia semakin meningkat, terutama dikota-kota besar. Seperti halnya di Jakarta kita akan sangat mudah menemui anak jalanan diberbagai tempat, mulai dari perempatan lampu merah, stasiun kereta api, terminal, pasar, pertokoan dan bahkan mall. Keberadaan mereka mengundang keperihatinan bagi kita mengingat kehidupan jalanan amat rentan dengan hal-hal yang membahayakan baik bagi dirinya maupun orang lain dan juga permasalahan lainnya yang memicu munculnya permasalahan sosial. Tujuan : Penelitian ini bertujuan untuk menggali secara mendalam pemicu terjadinya hubungan seksual pranikah pada anak jalanan di Kota Makassar. Metode: Jenis Penelitian kualitatif menggunakan pendekatan fenomenologi, yang mengeksplorasi femomena hubungan seksual pranikah pada anak jalanan di Kota Makassar. Pengumpulan data dilakukan dengan observasi dan indepth interview. Informan kunci dalam penelitian ini adalah mucikari, informan pendukung adalah konsumen, dan informan biasa terdiri dari anak jalanan yang bersedia untuk turut dalam penelitian ini. Hasil: didapatkan informan sebanyak 9 orang yang terdiri dari 1 orang informan kunci, 1 orang informan biasa, dan 7 orang informan pendukung. Tanggapan informan mengenai perilaku seksual yang sangat memprihatinkan. Mereka bahkan secara terang-terangan mengakui pernah melakukan hubungan seks pranikah. Gaya hidup anak jalanan, khususnya masalah seks sudah tidak terbendung lagi. Mereka sudah menikmati gaya hidup yang bebas. Teman sebaya menunjukkan bahwa mereka dominan saling mengajak satu dengan yang lainnya untuk melakukan hubungan seks pranikah. Pada umumnya orang tua mereka kurang memperhatikan pergaulan anaknya sehingga menyebabkan anak melakukan hubungan seks pranikah. Kesimpulan: Hampir semua informan memiliki personal atau pribadi yang baik. Pemerintah kota Makassar khususnya dinas sosial, diharapkan memberikan perlindungan dan menampung aspirasi anak jalanan, bukan hanya sekedar menertibkannya serta memberikan keterampilan yang bermanfaat sehingga anak jalanan tahu dimana harus menyalurkan bakat mereka dengan dukungan pemerintah setempat.
\end{abstract}

\section{Abstract}

Background: Street children are a reality that is very clear and close to our daily lives. Today, the growth of street children in Indonesia is increasing, especially in big cities. As in Jakarta, it is very easy to meet street children in various places, from red light intersections, train stations, terminals, markets, shops and even malls Their presence brings concern to us considering that street life is very vulnerable to things that are harmful to both themselves and others as well as other problems that trigger social problems. Objective: This study aims to explore in depth the triggers of premarital sexual relations in street children in Makassar City Method: This type of qualitative research uses a phenomenological approach, which explores the phenomenon of premarital sexual relations in street children in Makassar City. Data collection was carried out by observation and indepth interviews. Key informants in this study were pimps, supporting informants were consumers, and regular informants. Consisted ofstreed children who were willing to participate in this study. Results: : There were 9 informants consisting of 1 key informant, 1 regular informant, and 7 supporting informants. Informants' responses regarding sexual behavior were very concerning. They even openly admit to having had. premarital sex. The lifestyle of street children, especially the problem of sex, is unstoppable. They already enjoy a free lifestyle. Peers showed that they were dominant in inviting each other to have premarital sex. In general, their parents pay less attention to their child's association, causing children to have premarital sex. Conclusion: Almost all informants have a good personal or personality. The Makassar city government, especially the social service, is expected to provide protection and accommodate the aspirations of street children, not just to discipline them and provide useful skills so that street children know where to channel their talents with the support of the local government 


\section{PENDAHULUAN}

Kota Makassar merupakan kota metropolitan semakin maraknya dengan perilaku seks bebas. Hampir4.000-an penderita AIDS di Sulawesi selatan, sekitar 3.134 penderita atau sekitar 80 persen berada diKota Makassar. Bahkan Kota Makassar, disebut termasuk kota penderita HIV/AIDS tertinggi di Indonesia, setelah Jayapura dan Jakarta (Ksrpmiunhas 2017).

Anak jalanan di Indonesia masih belum dianggap sebagai kelompok dengan resiko tinggi terkena HIV-AIDS. Namun Departemen Kesehatan RI menyatakan bahwa anak yang hidup di jalanan lebih rentan terkena virus HIV-AIDS Hal ini didukung oleh Depkes RI tahun 2010 yaitu 144.889 anak yang hidup dijalanan, lebih terinfeksi HIV (Hanifah,2010.

Permasalahan yang dihadapi anak jalanan diantaranya kurangnya pemenuhan kebutuhan dasar seperti Pendidikan, perlindungan, kasih saying, kesehatan, makanan, minuman dan pakaian. Akhirakhir ini dijumpai masalah yang lebih serius seperti trafficking, eksploitasi seks komersial dan berbagai tindak kekerasan. Mereka kerap mengalami ekploitasi ekonomi oleh orang dewasa termasuk orang tuanya, rentan terhadap kekerasan fisik, sosial dan seksual, sering terpaksa harus menjadi pengguna dan pengedar narkoba atau terlibat kejahatan (Depsos, 2011).

Fenomena anak jalanan yang terjadi di Kota Makassar sangat menarik untuk dicermati terutama efek pada hubungan seksual yang mungkin timbul. Kecenderungan hidup bebas dijalanan memberikan dampak bagi hubungan seksual bebas dikalangan anak jalanan. Perilaku seksual tersebut menjadi pemicu awal munculnya kelompok anak jalanan yang rentan terhadap terjadinya kehamilan yang tidak diinginkan, infeksi menular seksual (IMS) dan infeksi HIV/AIDS (Sutiana, 2011).

Anak jalanan sebagian besar menghabiskan waktunya untuk mencari nafkah atau berkeliaran. Dengan umur dibawah 16 tahun yang sudah melepaskan diri dari keluarga, sekolah dan lingkungan masyarakat terdekatnya, serta larut dalam kehidupan yang berpindah-pindah ke jalan raya. (Arief, 2012)

Berdasarkan data WHO, remaja adalah penduduk dalam rentan usia 10-19 tahun, menurut peraturan Menteri Kesehatan RI Nomor 25 tahun 2014, remaja adalah penduduk dalam rentag usia 10-18 tahun dan menurut Badan Kependudukan dan Keluarga Berencana (BKKBN) rentang usia remaja adalah 10-24 tahun dan belum menikah. Jumlah kelompok usia 10-19 tahun di Indonesia menurut sensus penduduk 2010 sebanyak 43,5 juta atau sekitar $18 \%$ dari jumlah penduduk. Di dunia di perkirakan kelompok remaja berjumlah 1,2 milyar atau $18 \%$ dari jumlah penduduk dunia (WHO, 2014).

Beberapa hasil survey yang dilakukan pada anak jalanan sebanyak 1284 orang anak jalanan. Kehidupan jalanan memberikan kemudahan serta peluang untuk hubungan seksual. Jumlah tersebut ditemukan sebanyak $6,9 \%$ pernah melakukan hubungan seksual. Pasangan dalam berhubungan seksual pun bervariasi. Mereka dengan mudah biasa berhubungan dengan pekerja seks dan ganti-ganti pasangan sesama anak jalanan, melakukan seks tanpa kondom, atau ia sendiri sebagai pekerja seks. Sebanyak $12,4 \%$ anak jalanan mengaku pernah melakukan hubungan sejenis, 46,1\% mengaku melakukannya dengan pacar, bahkan $12,4 \%$ pernah melakukannya dengan pekerja seks. Ditemukan pula 2 orang anak jalanan yang mengaku sebagai pekerja seks. Bagi sebagian anak perempuan jalanan, kehidupan seks merupakan bagian dari kehidupan mereka di jalanan sehingga mereka mulai terbiasa untuk melakukan prostitusi agar memperoleh uang (Rikawarastuti, 2013)

Beberapa hasil survey yang dilakukan pada beberapa remaja anak jalanan di kota Surakarta sebanyak 20 orang didapatkan data 93 persen remaja anak jalanan telah memiliki pacar sedangkan data terhadap perilaku seksual pra nikah 80 persen pernah 
melakukan ciuman pipi dengan pacar, 73,3 persen pernah melakukan ciuman bibir dengan pacar, 60 persen mengatakan pernah memegang alat kelamin pacar dan 46,7 persen pernah melakukan coitus (Purwaningsih et al 2012).

Perilaku seksual berisiko pada remaja yang banyak terjadi di masyarakat diperkuat dengan hasil penelitian yang dilakukan oleh Prastiwi (2012) pada remaja yang menunjukkan bahwa dari 100 orang responden yang diambil secara acak terdapat $76 \%$ responden melakukan tindakan seksual pasif (berciuman, meraba, dan petting) dan $24 \%$ responden lainnya melakukan tindakan seksual aktif atau sexual intercourse. Kuatnya pengaruh peran teman sebaya pada anak jalanan menjadikan mereka untuk mempunyai sikap dan perilaku seksual yang tidak sehat yang ada akhirnya mendekatkan mereka pada resiko terinfeksi berbagai macam penyakit menular seksual termasuk di dalamnya HIV dan AIDS. Karena pergaulan bebas yang mendorong mereka untuk melakukan perilaku seks bergantiganti pasangan atau kecenderungan memakai narkoba menjadikan mereka semakin berisiko bagi kesehatan dan masa depan mereka ini menjadi sebuah ancaman besar bagi keberlangsungan suatu bangsa (Setyowati, 2012).

Berdasarkan hasil penelitian dimana anak jalanan yang mempunyai teman pernah melakukan hubungan seksual cenderung 3 kali lebih tinggi untuk berperilaku seksual pranikah daripada anak jalanan yang tidak punya teman yang melakukan hubungan seksual (sutjiningsih, 2014).

Tidak kalah pentingnya adalah peran orang tua dalam mengontrol pergaulan anak. Pada anak jalanan, peran pengawasan orang tua tentu saja sangat longgar. Remaja yang sebagaian besar waktunya di jalan bahkan tidak pulang ke rumah tentu saja semakin menambah kompleksitas permasalahan sosial termasuk pergaulan bebas pada anak jalanan. Menurut Efendy (2012), bahwa peran orang tua dalam mendidik anaknya amat menentukan pembentukan karakter dan perkembangan kepribadian anak.
Saluran komunikasi yang baik antara orang tua dan anaknya dapat menciptakan suasana saling memahami terhadap berbagai jenis masalah keluarga, terutama tentang problematika remaja, sehingga kondisi ini akan berpengaruh terhadap sikap maupun perilaku yang akan dibawakan anak sesuai dengan nilai yang ditanamkan orang tua.

Hasil penelitian Rikawarastuti (2013) menunjukkan bahwa dari tingkat hubungan dengan orang dewasa lebih banyak yang merasa memiliki hubungan yang kurang baik $(62,3 \%)$. Salah satu orang dewasa yang dimaksud adalah orang tua. Meskipun banyak responden yang tinggal dengan orang tua, namun masih banyak responden yang merasa memiliki hubungan kurang baik. Hal tersebut menunjukkan bahwa kedekatan fisik antara anak jalanan dan orang tua tidak otomatis menimbulkan kedekatan secara emosional. Hubungan yang terbangun hanya hubungan formalitas antara anak dan orang tua dan tidak menyentuh masalah yang substansial.

Berdasarkan hasil penelitian Ahmad Taufik (2013) bahwa berbagai macam penyebab para remaja melakukan seks pranikah mulai dari adanya dorongan biologis atau seksual (sexual drive) yang sudah tidak dapat mereka bendung dan dilakukan semata-mata untuk memperkokoh komitmen dalam berpacaran, adanya permasalahan dalam keluarga seperti kurangnya mendapatkan kasih sayang dari orang tua, kurangnya iman tidak mengingat Tuhan Yang Maha Esa, sering keluar malam (pergaulan bebas) walaupun tidak ada urusan penting.

Dari hasil penelitian Elisabet (2014) menunjukkan bahwa mayoritas anak jalanan berusia lebih dari 17 tahun (62\%). Tingkat permisvitas anak jalanan yang berusia lebih dewasa dan lebih muda hamper sama. Hal itu dimungkinkan karena rentang usia anak jalanan hanya 4 tahun dan mereka tinggal dilingkukan yang sama Proporsi anak jalanan yang berjenis kelamin laki-laki dan perempuan seimbang dengan tingkat permisvitas laki-laki lebih tinggi dibanding dengan perempuan $(69,7 \%$ dan $29,4 \%)$. Hal 
ini menunjukkan bahwa jenis kelamin mempunyai pengaruh paling kuat untuk menjadikan anak jalanan bersikap lebih permisif dari perempuan.

Perilaku hubungan seksual yang dilakukan anak jalanan di Kota Makassar semakin berisiko karena dilakukan sebelum menikah dan tanpa penggunaan kondom sebanyak 95 responden yang telah berhubungan seksual sebelum menikah terdapat 75,8\% tidak menggunakan kondom ketika berhubungan seksual. Hubungan sekual yang dilakukan anak jalanan di Kota Makassar sudah sangat memprihatinkan. Hal ini dikarenakan hubungan seksual yang dilakukan bukan saja secara vaginal, melainkan oral dan anal (Amiruddin, 2013). Adapun data anak jalanan untuk wilayah Makassar, berdasarkan rekapitulasi data PMKS (Penyandang Masalah Kesejahteraan Sosial) Kota Makassar pada tahun 2015 jumlah anak jalanan meningkat menjadi 918 orang yang tersebar di 14 Kecamatan di Makassar, dengan jumlah terbanyak di Kecamatan Manggala sebanyak 307 anak jalanan. Jumlah anak jalanan dari tahun sebelumnya tercatat sebanyak 794 orang. Dan data yang ditemukan di dinas sosial Makassar bahwa dari 15 anak jalanan tersebut ada yang telah melakukan hubungan seksual pranikah sampai mengalami kehamilan. (Dinsos Makassar, 2015).

Kota Makassar merupakan salah satu kota dengan penderita HIV/AIDS tertinggi diprovinsi Sulawesi Selatan. Dari hasil observasi awal yang dilakukan di Kelurahan Karunrung Kecamatan Rappocini Kota Makassar yang merupakan wilayah denga jumlah anak jalanan 134 jiwa. Dari jumlah anak jalanan tersebut di temukan ada 35 anak yang mengaku pernah melakukan hubungan seks bebas. Rentang usia anak jalanan rata-rata berusia 15-21 tahun, dan rata-rata pendidikannya ada yang tamatan Sekolah Dasar (SD) sampai Sekolah Menengah Pertama (SMP) Berdasarkan data tersebut peneliti berniat untuk melakukan observasi lebih lanjut mengenai
"Hubungan Seksual Pranikah Pada Anak Jalanan Di Kota Makassar

\section{BAHAN DAN METODE}

Penelitian ini dilakukan di Kota Makassar. Penelitian ini menggunakan metode penelitian kualitatif. Metode ini digunakan untuk mengeksplorasi fenomena mengenai hal-hal yang menjadi-alasan anak jalanan melakukan hubungan seksual pranikah dengan cara observasi, wawancara mendalam dan dokumentasi selama penelitian berlangsung.

Tabel 1. Karakteristik Subjek Penelitian

\begin{tabular}{|c|c|c|c|c|c|c|}
\hline p & Inisial & $\begin{array}{c}\text { Jenis } \\
\text { Kelamin }\end{array}$ & $\begin{array}{l}\text { Usia } \\
\text { (Th) }\end{array}$ & $\begin{array}{c}\text { Pekerjaan / } \\
\text { jurusan }\end{array}$ & Alamat & $\begin{array}{l}\mathrm{K} \\
\text { et }\end{array}$ \\
\hline 1 & Dnl & Laki-laki & 20 & $\begin{array}{c}\text { Anak } \\
\text { jalanan }\end{array}$ & $\begin{array}{l}\text { Jipang } \\
\text { raya } 1\end{array}$ & IB \\
\hline 2 & Ism & Perempuan & 17 & $\begin{array}{c}\text { Anak } \\
\text { jalanan }\end{array}$ & $\begin{array}{c}\text { Karaeng } \\
\text { bonto } \\
\text { tangnga }\end{array}$ & IB \\
\hline 3 & Adp & Perempuan & 15 & $\begin{array}{c}\text { Anak } \\
\text { jalanan }\end{array}$ & $\begin{array}{c}\text { Karaeng } \\
\text { bonto } \\
\text { tangnga' }\end{array}$ & IB \\
\hline 4 & Iyn & Laki-laki & 17 & $\begin{array}{c}\text { Anak } \\
\text { jalanan }\end{array}$ & $\begin{array}{l}\text { Jipang } \\
\text { raya } 2\end{array}$ & IB \\
\hline 5 & $\mathrm{Nzq}$ & Laki-laki & 21 & $\begin{array}{c}\text { Anak } \\
\text { jalanan }\end{array}$ & $\begin{array}{l}\text { Jipang } \\
\text { raya } 1\end{array}$ & IB \\
\hline 6 & Rdl & Laki-laki & 19 & $\begin{array}{c}\text { Anak } \\
\text { jalanan }\end{array}$ & $\begin{array}{c}\text { Karaeng } \\
\text { bonto } \\
\text { tangnga' }\end{array}$ & IB \\
\hline 7 & Ull & Laki-laki & 17 & $\begin{array}{c}\text { Anak } \\
\text { jalanan }\end{array}$ & $\begin{array}{l}\text { Jipang } \\
\text { raya } 1\end{array}$ & IB \\
\hline 8 & $\mathrm{Km}$ & Laki-laki & 35 & $\begin{array}{c}\text { Kasi anak } \\
\text { jalanan }\end{array}$ & $\begin{array}{c}\text { Ar } \\
\text { hakim }\end{array}$ & IK \\
\hline 9 & Ssh & Perempuan & 42 & $\begin{array}{c}\text { Kader anak } \\
\text { jalanan }\end{array}$ & $\begin{array}{c}\text { Karaeng } \\
\text { bonto } \\
\text { tangnga' }\end{array}$ & IP \\
\hline
\end{tabular}

Sumber : Analisa penulis 2017

Berdasarkan hasil penelitian didapatkan data bahwa informan dengan kelompok umur 15 tahun (1 orang), 17 tahun (3 orang), umur 19 tahun (1 orang), umur 20 tahun (1 orang), umur 21 tahun (1 orang). Remaja pada kelompok menengah rentan usia 15-21 tahun mengalami perubahan-perubahan dalam aspek kognitif, emosi, dan moral, diantara masa-masa anakanak menuju dewasa. Berbagai usia informan yang berada pada fase pencarian jati diri dan labilitas serta pengaruh oleh lingkungan sekitarnya, pada usia tersebut berbagai jenis kebutuhan remaja yang telah 
di komplikasikan dari kebutuhan psikologis yang mendasar, salah satunya mengenai kebutuhan remaja adalah pada masa remaja pada umumnya merindukan pengalaman baru, rasa aman, respons dan pengakuan, diusia ini sering kali merasa bahwa rumah tempat tinggal telah memberi monotomi, rasa tidak aman, dan penolakan, penyimpangan yang dilakukan kadangkadang dapat digambarkan sebagai upaya yang salah arah untuk menemukan kepuasan atau pemenuhan atas keinginan-keinginan yang paling fundamental

\section{HASIL PENELITIAN}

Dari hasil yang dilakukan penelitian ini dilakukan selama 1 bulan dan lokasi penelitiannya itu berada di Kelurahan Karunrung Kecamatan Rappocini Kota Makassar. Penelitian ini dilakukan terhadap 9 informan mengenai perilaku seksual berisiko khususnya di kota makassar bahwa ada beberapa kesamaan dari jawaban dari pihak informan atas pertanyaan-pertanyaan mengenai fenomena perilaku seksual beresiko yang ada di kota makassar, meskipun tanggapan informan yang satu dengan yang lainnya berbeda dalam menanggapi tetapi pada intinya jawaban informan mempunyai maksud yang sama. Beberapa informan mengatakan yang memacu untuk melakukan hubungan seks bebas yaitu dikarenakan terpancing oleh nafsu ketika sedang berduaan dan di tempat yang sepi. Seperti yang diungkapkan informan dibawah ini Berdasarkan pernyataan informan tersebut maka informan khususnya 7 anak jalanan mengatakan hal yang terkait tentang pergaulan bebas pada seperti di bawah ini "juga kalau datang mii nafsu ku biasa ku ajak ki pergi ke tempatnya temanku untuk lampiaskan nafsu ku, karena pacarku kalau ku ajak mau jii juga". (RDL, 19 tahun tgl 0508-2017)

Berdasarkan dari jawaban informan bahwa memang yang memacu untuk melakukan hubungan seks bebas pada anak jalanan itu karena terpancing oleh nafsu. Dan mereka juga tidak malu lagi untuk memperlihatkan ke teman-teman mereka jika mengajak pacarnya untuk melakukan hubungan seksual. Informan mengatakan bahwa sekarang ini hubungan seksual sudah biasa sehingga anak jalanan yang berpacaran sudah melewati batas. Tempat sepi merupakan tempat paling strategis untuk melakukan hubungan seksual, dan salah satu yang menjadi faktor timbulnya nafsu yaitu dari perempuan atau laki-laki itu sendiri “.. biasa kalau didatangi kh pacarku baru pakaian seksi ki deh ku sukanya (celana pendek dan baju kaos tanpa lengan), apalagi kalau datangki suara jabenya. Auuu... tidak bisa maka tahanki langsung saya ajak pergi ke tempat sepi”. (ULL. 17 tahun 31-08-2017)

Infoman tersebut sudah mengetahui bahwa ketika melihat pasangannya berpakaian terbuka maka nafsunya akan terpancing untuk melalukan hubungan seksual. Informan mengatakan bahwa hubungan seksual pranikah dikalangan anak jalanan sudah dianggap biasa bahkan hal itu dilakukan hanya untuk bersenang-senang dan melampiaskan nafsu sesaat "Untuk pegangan tangan ya kadang-kadang, biasanya dilakukan di perempatan lampu merah kadang juga di jembatan. Kalo berpelukan jarang, biasanya b.erpelukan karena pengen aja biasa saya lakukan di tempat sepi/gelap Berciuman pernah dan sering dilakukan karena "enak" biasa saya lakukan di tempat sepi terutama bila nggak ada orang. Kalo menyentuh/meraba daerah erotis tidak pernah.. (DNL. 20 tahun 17-082017

Berdasarkan dari jawaban informan bahwa perilaku seksual tingkah laku yang didorong oleh hasrat seksual, baik dengan lawan jenisnya maupun dengan sesama jenis mulai dari perasaan tertarik sampai tingkah laku berkencan, bercumbu, dan bersenggama "Berpegangan tangan dan berpelukan pernah tapi jarang. Kalo berciuman pernah karena kepengen tapi jarang. Menyentuh daerah erotis pernah karena kepengen aja kalo liat bagian tubuh wanita yaitu bagian dada kemudian timbul keinginan untuk megang. Kalo melakukan 
pernah tapi kadang kadang, dilakukan dengan pacar atas dasar suka sama suka dilakukan hampir selama empat bulan berulang kali dan diperbuat tanpa menggunakan alat kontrasepsi, biar tidak hamil pacar saya minum jamu pelancar haid. Kalo onani pernah, kadang kadang hal ini disebabkan karena sering melihat video porno melalui seluler dan kebiasaan ini sering dilakukan secara bersama sama tetapi untuk onani dilakukan tanpa sepengetahuan orang lain. Trus oral seks dengan pacar pernah dan sering karena lihat di videovideo porno serta menimbulkan sensasi yang berbeda" (NZQ. 21 Thn. 31-08-2017

Berdasarkan penjelasan tersebut dapat diketahui bahwa selama menjadi anak jalanan telah melakukan perilaku seksual yang bebas mulai dari berpegangan tangan, berpelukan, berciuman, meraba, bersenggama, onani dan oral seks. "Kalo berpegangan tangan, berpelukan dan berciuman pernah dan sering, kalo menyentuh daerah erotis/meraba pernah dan sering dilakukan karena menikmati. Untuk bersenggama pernah dan sering juga, pakai kondom tapi jarang biasanya alat kontrasepsi di dapat dari menitip teman di apotik. Onani pernah tapi jarang kalo lagi kepengen aja. Oral seks pernah juga tapi jarang" (IYN. 17 Thn. 31-08-2017).

Berdasarkan keterangan di atas dapat diketahui bahwa sudah terbiasa melakukan perilaku seksual secara bebas bahkan untuk mengulangi perilaku seksual tersebut ternyata informann sudah sering menggunakan kontrasepsi sebagai pengaman agar pacarnya tidak hamil "Berpegangan tangan, berpelukan dan berciuman pernah dan sering, kalo menyentuh daerah intim pernah karena dengan teman dekat pacar." (ADP. 15 Thn. 13-08-2017). Berdasarkan keterangan di atas menunjukkan bahwa sudah pernah melakukan perilaku seksual seperti berpegangan tangan, berpelukan, berciuman, meraba/menyentuh daerah erotis, bersenggama, dan oral seks. "Melakukan pernah, karena dilakukan sudah lama sehingga bisa dikatakan menjadi sebuah kebutuhan terkadang tidak memakai kondom" (ISM. 17 Thn. 13-082017).

Berdasarkan keterangan di atas bahwa sebagian besar subyek penelitian ini pernah melakukan perilaku-perilaku seksual mulai dari berpegangan tangan, berpelukan, berciuman, meraba, onani dan oral seks. Terutama untuk anak jalanan yang berjenis kelamin perempuan untuk perilaku seksual awal mulanya cenderung karena adanya unsur paksaan/ancaman dari orang lain baik dari pacar maupun sesame anak jalanan. Berdasarkan pernyataan informan tersebut maka informan pendukung (Kader Anak Jalanan) juga mengatakan hal yang terkait tentang pergaulan bebas pada anak jalanan di Kota Makassar seperti di bawah ini : "Apa yang terjadi di Makassar khususnya perilaku seksual sudah hal yang biasa menurut remaja saat ini, khususnya anak jalanan, dimana persepsi dia bahwa dalam melakukan hubungan seksual tidak perlu dipikirkan dampak negatif ketika melakukan hubungan seks, mereka hanya memikirkan kenikmatan yang dirasakan, dan itulah yang menjadi masalah sosial yang ada di sekeliling kita, jadi sebagai kader, saya hanya berharap sentuhan dari pemerintah setempat agar lebih memperhatikan remaja kota khususnya bagi anak jalanan untuk di bina menjadi lebih baik (SSH, 42 Thn. 14-08-2017).

Berdasarkan informan pendukung, bahwa maraknya pergaulan bebas yang terjadi di masyarakat sekitar khususnya anak jalanan yang ada dimakassar dapat menjadi perhatian khususnya pemerintah kota Makassar bahwa untuk menekan angka perilaku seksual pranikah maka sebaiknya anak jalanan diberi keterampilan khusus dan memberikan edukasi bahwa sebaiknya tidak melakukan seksual pranikah karena akan berdampak buruk kepada remaja itu sendiri. Berdasarkan pernyataan informan kunci (Kepala Seksi Anak Jalanan Dinas Kota Makassar) juga mengatakan hal yang terkait tentang pergaulan bebas pada anak jalanan di Kota Makassar seperti di bawah ini : “ Pernah ada di dapatkan kasus seperti itu, 
memang dari segi aturan, norma agama tidak boleh, seharusnya kan dia melalui proses hukum dan norma agama yang seharusnya. Dan kami selaku dari dinas sosial tidak mengharapkan adanya kejadian seperti itu. Makanya selalu kita mengadakan patroli dan melakukan pembinaanpembinaan terhadap anak jalanan ataupun saat ini namanya anak punk, biasanya juga mereka berkelompok baik laki-laki maupun perempuan, kalau kita dapatkan di situ ada anak perempuan maka kita usahakan dan menganjurkan untuk mereka pulang ke rumah". (Km,35 thn,14-08-2017)

Berdasarkan penjelasan Informan Kunci (Kasi Anak Jalanan Dinas Sosial) bahwa pergaulan bebas anak jalanan di Kota Makassar sudah melewati batas pergaulan yang sebenarnya, bahkan sudah melewati batas norma agama. Sebaiknya jika ditemukan mereka melakukan pergaulan seks bebas seharusnya ditindak dan diberikan proses hukuman yang selayaknya. Sering kali juga informan melakukan patroli pada anak jalanan dan melakukan pembinaan, dan jika ditemukan ada anak perempuan ketika dilakukan patroli biasanya di anjurkan untuk pulang ke rumahnya. Berdasarkan data yang di dapatkan peneliti melihat bahwa memang petugas dari dinas sosial seringkali mengadakan patroli di sepanjang kota Makassar dan sering kali mendapatkan anak jalanan.

Faktor penyebab menjadi anak jalanan pada subyek penelitian ini yaitu faktor ekonomi, faktor modeling dan faktor disorganisasi keluarga (perpecahan keluarga). Faktor ekonomi cenderung akibat adanya kemiskinan, sehingga anak terpaksa mencari nafkah untuk membantu memenuhi kebutuhan hidup keluarganya atau untuk kebutuhan pribadinya sebagaimana yang dialami oleh anak jalanan disebabkan oleh faktor modeling (sejak kecil sudah berada di jalanan). Selanjutnya faktor disorganisasi keluarga atau adanya perpecahan keluarga juga menjadi penyebab menjadi anak jalanan. Anak sering dijadikan pelampiasan atas masalah yang tengah dihadapi orang tua, sehingga anak stres dan tidak betah di rumah, maka anak akan melarikan diri dan mencari kehidupan lain kemudian terjebak dalam kehidupan jalanan.

Berdasarkan hasil penelitian, sebagian besar anak jalanan pernah melakukan perilaku-perilaku seksual mulai dari berpegangan tangan, berpelukan, berciuman, meraba, bersenggama, masturbasi/onani dan oral seks. Bahkan ada juga yang beberapa kali pernah melakukan hubungan seksual dengan bergonta - ganti pasangan tanpa menggunakan kondom dan dibawah pengaruh alcohol. Selain itu perilaku anak jalanan yang kami wawancarai mengaku setiap harinya mereka melakukan hubungan seksual 2 hingga 3 hari dan biasanya mereka melakukan hubungan seksual di bawah kolom jembatan dan tempat - tempat dimana tidak dilalui oleh masyarakat sekitar. Terutama untuk anak jalanan yang berjenis kelamin perempuan untuk perilaku seksual awal mulanya cenderung karena adanya unsur paksaan/ancaman dari orang lain baik dari pacar maupun sesama anak jalanan. Anak jalanan biasanya melakukan oral seks bersama pacarnya di kolong jembatan atau ditempat dimana dia biasa melakukan hubungan seks, namun sebelum melakukan hubungan seks, mereka biasanya melakukan oral terlebih dahulu sebagai pemanasan sebelum benar-benar melakukan hubungan seksual yang lebih dalam mengatakan senang karena kenikmatan yang dirasakan dalam berhubungan. Hal ini ditandai ketika peneliti mengobservasi anak jalanan, hampir semua merespon dengan wajah atau mimik yang senang atau bahagia, adapula yang mengatakan bahwa melakukan hubungan seksual adalah kenikmatan surga dunia yang amat nikmat sehingga anak jalanan semakin sulit untuk mengontrol dirinya dalam melakukan hubungan seksual yang hampir dilakukan setiap harinya. Kehidupan anak jalanan yang ada di kota Makassar setiap tahunnya mengalami peningkatan. Hal ini karena bertambahnya penduduk miskin dan juga terbatasnya akses mereka sehingga ia 
lebih memilih menjadi anak jalanan. Dari hasil wawancara, hampir semua anak jalanan pernah melakukan hubungan seksual pranikah. Hal ini menjadi prihatin untuk generasi penerus bangsa, sebagian mereka tidak menyadari bahwa apa yang dilakukan itu dapat merusak masa depannya. Namun untuk berpikir jauh dari seperti itu, sepertinya anak jalanan tidak memikirkan hal tersebut, mereka hanya ingin melakukan hubungan seks pranikah. Terdapat anak jalanan yang mengaku bahwa apa yang selama ini mereka lakukan dapat menikmati sensasi yang luar biasa apalagi ditambah dengan minuman beralkohol dan melakukan hubungan seksual semakin terasa nyaman

Berdasarkan informasi pula bahwa apabila tidak melakukan hubungan seksual, maka untuk menyalurkan hasratnya, anak jalanan melakukan onani/masturbasi pada pagi hari. Hal ini yang sering dilakukan oleh para anak jalanan. Adanya pengaruh video porno yang sering mereka saksikan melalui handphone tersimpan dipikiran anak jalanan, sehingga apabila tidak ada tempat pelampiasan mereka melakukan onani. Namun biasanya anak jalanan melakukan hubungan seksual dengan pacarnya tidak menggunakan kondom, mereka menganggap bahwa dengan menggunakan kondom tidak membuat merasa nyaman karena menurut anak jalanan ada perbedaan kenyamanan ketika menggunakan kondom dengan tidak menggunakan, disamping itu anak jalanan tidak menggunakan kondom karena terkendala biaya, walaupun harganya murah, namun bagi anak jalanan itu menjadi mahal sehingga para anak jalanan enggan menggunakan kondom ketika melakukan hubungan seksual.

Pada dasarnya anak jalanan yang ada di kota Makassar melakukan perilaku seksual karena didorong oleh nafsu yang membuatnya merasa lupa akan dampak yang ditimbulkan ketika melakukan hubungan seksual. Hal ini membuat anak jalanan itu sendiri bebas melakukan perilaku seks ditambah dengan pengaruh minuman beralkohol yang dengan mudahnya anak jalanan melakukan seks pranikah. Namun ada juga anak jalanan yang mengaku pernah melakukan hubungan seksual lebih dari satu perempuan pada saat melakukan hubungan seksual secara bersama-sama, anak jalanan mengatakan bahwa apa yang mereka lakukan hanyalah untuk mencari kesenangan, terlepas dari semua itu, bahaya seks pranikah akan memberi dampak buruk

\section{KESIMPULAN}

Perilaku seksual berisiko anak jalanan dalam penelitian ini sangat mengenai dampak-dampak dari perilaku seksual, rentan melakukan perilaku seksual karena usia pengetahuan dari mereka masih sangat minim mereka yang dalam tahap perkembangan anak jalanan tentang hal-hal terkait seksualitas. Anak jalanan memiliki rasa ingin tahu yang besar terhadap mengetahui cara melakukan perilaku seksual dan hal-hal baru dan dorongan untuk mencoba-coba hanya dampak dari hubungan seks bebas

\section{SARAN}

Disarankan kepada pihak yang berkompeten untuk memberikan pendidikan tentang perilaku seksual, mendatangi rumah-rumah singgah anak jalanan atau tempat yang biasa anak jalanan berkumpul dan kepada pihak terkait hendaknya terus melakukan pendidikan kesehatan reproduksi pada anak jalanan sehingga akan menambah ilmu pengetahuan tentang prilaku seksual pranikah di program kesehatan reproduksi remaja.

\section{DAFTAR PUSTAKA}

A Amiruddin, Ridwan, and Fitri Yanti. "Tindakan Beresiko Tertular HIVAIDS Pada Anak Jalanan Di Kota Makassar." (2013)

Aras, S, Semin, S, Gunay, T, Orein, T, \& Ozan, S. (2014) Sexual Attitudes And Risk-Talking Behaviors of 
Highschoool in Turkey. J Sch, Health 77 (7) 359-366.

Bandura, A. (1997). Self Effcacy The Excersise of Control, New York:Freeman.

Banun, F., \& Setrorogo, S. (2013). FaktorFaktor Yang Berhubungan Dengan Perilaku Seksual Pranikah Pada Mahasiswa Semester V STIKES X Jakarta Timur 2012. Jurnal Ilmiah Kesehatan, 5 (1).

Dinsos Makassar, (2011). Rekapitulasi Data PMKS (Penyandang Masalah Kesejahteraan Sosial) Kota Makassar Pada Tahun 2011, Makassar. Dinas Sosial Makassar.=

Earle. J,. et al. 2007. Premarital sexual attitude and behavior at a religiously- affiliated university; two decades of changes. Sexuality \& culture. 1(2): p, 39-61.

Effendy, A. (2012). Perilaku Sehat, Kebiasaan Merokok Dan Minuman Keras Dikalangan Remaja Bali. Jakarta. PT Reneka Cipta.

Elisabet, A. (2012). Setya Asih Widyastuti, (2014). Personal Dalam Sosial Yang Mempengaruhi Sikap Anak Jalanan Terhadap Hubungan Seks Pranikah. Jurnal Promosi Kesehatan Indonesia. Vol 4, no.2 Agustus 2014.

Feriyanti, B., \& Fitri, A, R. (2010). Perilaku Seksual Pranikah Ditinjau Dari Intensitas Cinta Dan Sikap Terhadap Pornografi Pada Dewasa Awal. Jurnal Psikologi

Fitriana, N, G, (2012). Hubungan Pengetahuan Dan Sikap Tentang Seks Pranikah Dengan Perilaku Seksual Pada Siswa SMK XX
Semarang. Jurnal Komunikasi Kesehatan, 3 (01).

Galuh Walistiani, (2014). Perbedaan Diri Anak Jalanan Ditinjau Dari Status Anak Jalanan Di Surabaya. Vol 03 no. 2.

Hanifah, Abu. (2010). Penanganan Anak Jalanan Melalui Pemberdayaan Keluarga. Jurnal Informasi, Vol. 15 no. $2 .=$

Hariadi, dkk. (2009). Anak Jalanan Di Jawa Timur Masalah Dan Upaya Penanganannya. Surabaya University Press.

Hurlock, E. B. (2004). Psikologi Perkembangan: Suatu Pendekatan Sepanjang Rentang Kehidupan. Jakarta: Erlangga.

Irmawaty, S. (2013). Perilaku Seksual Pranikah Pada Mahasiswa. Jurnal Kesehatan Masyarakat, 9(1), 44-52.

John, S. (2003). Adolesence (Perkembangan Remaja) (Vol. Edisi 6). Jakarta Erlangga.

Ksrpmiunhas. (2017). Fenomena Seks Bebas Pada Kalangan Remaja di Kota Makassar. http://www.ksrpmiunhas.or.id./2017 /11/fenomena-seks-bebas-padakalangan-remaja.

Lubis, L. N. (2013) Psikologi Kespro Wanita Dan Perkembangan Reproduksi. Jakarta: Rineka Cipta.

Maryatun. (2013). Peran Teman Sebaya Terhadap Perilaku Seksual Pranikah Pada Remaja Di SMA Muhammadiyah 3 Surakarta. Gaster (Vol.10, No. 1 (2013): Februari), 2947. 
Mughnizah, (2013). Survey Tindakan Beresiko Terhadap Kesehatan Pada Anak Jalanan Di Kota Makassar Tahun 2013). Makassar: Fakultas Kesehatan Masyarakat Universitas Hasanuddin.

Purwaningsih, W. (2012). Hubungan Pengetahuan Dan Peran Keluarga Dengan Perilaku Seksual Pranikah Pada Remaja Anak Jalanan Di Kota Surakarta . Gaster, Jurnal Ilmu Kesehatan, 9(1), 22-29.

Rikawarastuti. (2013). Tinjauan Pendekatan Penanganan Perilaku Seksual Anak Jalanan. Jurnal Health Quality, (Vol. 4 No. 1 (2013) Nopember) Jakarta.

Sutyana, H. (2011). Revitalisasi Model Penanganan Anak Jalanan Di Rumah Singgah. Jurnal Ilmu Sosial dan Ilmu Politik, 15(1), 41-54.

Setiawan, H. (2014) 56\% Remaja Melakukan Hubungan Seks Di Luar Nikah.From $\underline{\text { Htps://awansx.wordpre }}$ ss.com/2014/08/15/56-remajamelakukan-hubungan-seks-di-luarnikah 